\title{
Pelvic Soft Tissue Necrotic Lesion
}

National Cancer Institute

\section{Source}

National Cancer Institute. Pelvic Soft Tissue Necrotic Lesion. NCI Thesaurus. Code C78525.

A necrotic process affecting the soft tissues of the pelvis. 